Clinical Medicine

Poster

Abstract ID: 142

\title{
Utilization of anterior segment optical coherence tomography (AS-OCT) enhanced high resolution corneal (EHRC) software in measuring Pterygium thickness
}

\author{
Mohd Radzi Hilmi ${ }^{\mathrm{a}}$ | Khairidzan Mohd Kamal ${ }^{\mathrm{b}}$ | Mohd Zulfaezal Che Azemin ${ }^{\mathrm{a}}$ | Azrin Esmady Ariffin ${ }^{\mathrm{c}}$ \\ ${ }^{a}$ Department of Optometry and Vision Sciences, Kulliyyah of Allied Health Sciences, International \\ Islamic University Malaysia \\ ${ }^{b}$ Department of Ophthalmology, Kulliyyah of Medicine, International Islamic University Malaysia
}

${ }^{c}$ Faculty of Optometry and Vision Science, SEGi University, Malaysia

Introduction: To propose an objective method of quantifying pterygium thickness using AS-OCT. Methods: Anterior segment imaging was performed using Enhanced High Resolution Corneal (EHRC) of Visante $\mathrm{T}^{\mathrm{TM}}$ OCT in 68 primary pterygium eyes. Prior to imaging, corneal topography assessment was performed on each pterygium eye in order to identify its topographic location. Based on topography mapping, three meridians (in degrees) were selected as close as possible to the pterygium border, which signify the demarcation of pterygium from the cornea. Reliability testing between intra and inter-observer on OCT imaging modality was examined using Intraclass correlation (ICC) and scatter plot. Results: The overall $(n=68)$ mean and SD of pterygium thickness via OCT modality were $0.48 \pm 0.10 \mathrm{~mm}(\mathrm{Cl}: 0.45-0.50)$. OCT imaging also showed excellent intra and intergrader reliability in measuring pterygium thickness with ICC of $0.997(\mathrm{Cl}: 0.994$ 0.998). Conclusions: We have described and demonstrated the use of EHRC as an objective measurement for pterygium thickness. This tool proved could eliminate the variability of human inter-graders in assessing thickness of pterygium with its promising ICC. This study had proved that anterior segment OCT imaging is a better choice in assessing pterygium compared to traditional slit-lamp biomicroscopy. We suggest that this tool is applicable for future work such as to understand the role thickness in pterygium morphology and its progression. Better understanding of pterygium morphology is important for future clinical decision, especially on prediction of induced corneal astigmatism and visual impairment due to pterygium.

KEYWORDS: Pterygium, anterior segment OCT, AS-OCT, thickness 